\title{
A Study of The Design Method and Similitude for A Small-Scale Test Drilling Rig (Part 1): An Application of The Geometrically Distorted Scaled Modeling Method
}

Mejbahul Sarker

Department of Petroleum Engineering, Faculty of Engineering, American University of Kurdistan, Duhok, Iraq.

*Corresponding Author: mejbahul.me@gmail.com

\begin{tabular}{l}
\hline Article History: \\
\hline Received: August 3, 2021 \\
Receive in Revised Form: September 1, 2021 \\
Accepted: September 10, 2021 \\
\hline
\end{tabular}

\section{Keywords:}

Full-size drillstring system, scaled drillstring model, scaling laws, scaling factor, vibrations, and simulation.

\begin{abstract}
Drillstrings often vibrate severely and tend to twist off during hard rock drilling. Therefore, dynamic testing is crucial in the design of drilling systems. Designers tend to employ the most powerful analytical tools, using the most elaborate electronic computers, however, actual testing is required to the designed system function optimally. In cases of enormous drilling systems, complex dynamic tests are often performed on a smaller-scale replica of the system, referred to as the model, which is more convenient, cost-effective, and time-effective. This study, therefore, describes the establishment of similar conditions among structural systems, with the main objective of studying the similitude theory's applicability in establishing the necessary similar conditions for designing scaleddown models to predict the drillstring's vibration behavior. The scaling laws for all the relevant parameters regarding the scaled drillstring model, as well as the full-size drillstring system, were derived from the respective equations of motion. The scaling factors for all relevant parameters are determined using the theory of dimensional analysis. In addition, the geometry distorted similitude theory is revisited and employed to overcome the physical limitation and develop the necessary similar conditions for dynamic testing of the scaled drillstring. Meanwhile, the similitude relationship between the prototype and the model was validated with a case study using lumped segments bond graph modeling and simulation software.
\end{abstract}

\section{INTRODUCTION}

The drilling industry is often faced several challenges, including severe drillstring vibrations which tend to minimize the life of the pipe by accelerating the process of fatigue. Furthermore, excessive vibrations have the capacity to cause pipe failure, wash-outs, and reduced penetration rate. For instance, in 2003, a company conducting drilling operations in Longhupao of Daqing, reported 7 malfunctions in the drillstring between the depths of 2,390 and 3,042 m, majorly due to excessive vibrations (Li et al., 2004). The high repair costs incurred led to the discontinuation of drilling activities in some areas of the well. Also, the repair operations required significant manpower, as well as material resources, and consequently reduced the drilling speed. These malfunction cases occur in the industry every year, therefore, the complex vibrational mechanisms of drilling systems must be completely understood to achieve improved performance and control of the functional operation.

Studies on the control of excessive drillstring vibrations were first carried out several decades ago (Finnie \& Bailey, 1960). Initially, these challenges were solved by developing dynamic models of the drillstring system, ranging from low order models based on lumped spring-mass approach (Eronini et al., 1982; Halsey et al., 1986), to high order elastodynamics and finite-element multibody models (Khulief et al., 2007; Khulief \& Al-Naser, 2005; Tucker \& Wang, 1999; A.S. Yigit \& Christoforou, 1996). However, 
these dynamic models were highly complex and numerous assumptions were made to simplify the models. Therefore, experimental studies of the drillstring dynamics are essential to complement the theoretical studies and reduce the model's complexity. Currently, only very few researchers have attempted to construct a laboratory-scale test rig to properly study the drillstring vibrational behavior.

Aarrestad \& Kyllingstad (1988) and Aarrestad \& Kyllingstad (1986) built a full-scale $1000 \mathrm{~m}$ vertical research drillstring and used a vertical drillstring, as well as a hard-wire measurement-while-drilling (MWD) tool. Subsequently, a theory for the torsional vibrational response on the longitudinal response for longitudinal excitation was presented. High data rate measurements of near the bit accelerations, weight on bit, and torque have been used to verify the theoretical predictions in drilling situations. Meanwhile, Antunes et al (1992) constructed an experimental drillstring model of a sample shaft and shell system with confined liquid. In this construction, a $1.5 \mathrm{~m}$ long, $0.75 \mathrm{~m}$ external radius, and $4 \mathrm{~mm}$ thick steel shaft was assembled vertically, with water as the drilling fluid, while the clearance between the central shaft and the rigid outer shaft was $11 \mathrm{~mm}$. Also, an electric motor with a speed control of up to $700 \mathrm{rpm}$ was been used to drive the shaft, while a $200 \mathrm{~N}$ shaker was used laterally to excite the mobile fixture, with a force excitation frequency of 0 to $25 \mathrm{~Hz}$.

In addition, Berlioz et al (1996) constructed a laboratory test rig to study the basic phenomena of lateral drillstring vibrations, using a $2 \mathrm{~m}$ long and 2 to $7 \mathrm{~mm}$ diameter steel string, as well as a 6 to $10 \mathrm{~mm}$ inner diameter plexiglass in the laboratory drilling set-up. Meanwhile, Khulief \& Al-Sulaiman (2009) constructed a laboratory-scale drillstring to study the combined vibrations mechanisms occurring within the drillstring's dynamic behavior, including bending, torsional, and self-excited stick-slip oscillations. A shaft of 1 to $2 \mathrm{~m}$ length and 0.3 to $1.0 \mathrm{~cm}$ diameter was used in this setup.

Loeken et al (2018) presented a laboratory-scale drilling rig to imitate the main functionality of a normal offshore drilling rig, using an aluminum drill pipe of $914.4 \mathrm{~mm}$ length, an outer diameter of $9.525 \mathrm{~mm}$, and a wall thickness of $0.889 \mathrm{~mm}$, installed during normal drilling operations with the rig. Recently, Khadisov et al (2020) designed a rig with fully functional and conducted successful experiments aimed at testing the drilling optimizations and failures. The rig has a complete hoisting system comprising actuators, stepper motors, and brakes, as well as a simple circulation system comprising two pumps with maximum flow rates and working pressures of $19 \mathrm{~L} / \mathrm{min}$ and 3.1 bar, respectively. A $6061 \mathrm{~T} 6$ aluminum alloy pipe with length, outer diameter, and wall thickness of $921.6 \mathrm{~mm}, 9.525 \mathrm{~mm}$, and $1.245 \mathrm{~mm}$, respectively, was used in this setup.

Based on the literature review, only a few laboratory-scale drillstring set-ups have been constructed for research on drillstring vibration, and these studies do not even consider the scaling analysis theory. The scaling laws provide the relationships between a full-scale structure (prototype) and the small-scale counterpart (model). Using the scaling laws, the prediction of the responses for the prototype is achieved by conveniently performing the dynamic testing on an in-expensive model which provides the benefits of convenience, cost-effectiveness, and time effectiveness. In cases where similar models are used, the relationship between the model and prototype must also be known. However, establishing this relationship and fulfilling the numerous similarity requirements between the two systems are often difficult to achieve. Therefore, this study focuses on deriving the scaling laws for the dynamic analysis of drillstring, including the difficulties faced in fulfilling the model design conditions between the two systems. Subsequently, the scaling laws are to be validated through a numerical modeling analysis.

This article comprises 9 sections, with sections 1 and 2 providing an introduction, as well as a description of modeling based on the conditions of the similarity, respectively. Furthermore, Section 2 presents a derivation of the scaling laws for the case of the drillstring dynamics, while section 4 describes the modes of the drillstring vibrations. Section 5 presents the scaling factors between the prototype and the scaled model to achieve the geometrical similarity and section 6 discusses the issues related to the geometrically similar scaled model construction. Meanwhile, Section 7 revisits the geometrically distorted scaling technique to derive a new set of scaling laws for achieving a laboratory-scaled drillstring model. Finally, section 8 presents a validation of the new scaling laws while Section 9 provides a conclusion for this study.

\section{METHODS}

\section{Modeling based on the conditions of similarity method}

A physical system refers to an assembly of engineering and/or parts of the natural physical world that respond individually or collectively to physical inputs by conversion into physical outputs. The behavior of the system is often investigated by experimental techniques, where the system is subjected to planned test conditions and the response is observed or measured. However, for larger or more complex systems, these investigations are preferably carried out on a smaller-scale replica, which provides the benefits of 
convenience, cost-effectiveness and time effectiveness. Experimental modeling is based on a mandatory condition stating the model and prototype system must obey the same physical laws. Therefore, the model must be constructed to embody the entire prototype's relevant features, as well as parts. This unique relationship between the two systems is broadly referred to as similarity, and is managed through modeling, an experimental technique essentially applied based on dimensional considerations. The condition of similarity between the systems is often established by a procedure called Dimensional Analysis. Therefore, modeling uses certain dimensional properties of the variables in the problem which are arranged in non-dimensional groupings (David, F W \& Nolle, 1982).

\section{Non-dimensional formulation based on Buckingham's theorem}

Usually, several variables, $\mathrm{x}_{1}, \mathrm{x}_{2}, \mathrm{x}_{3}, . ., \mathrm{x}_{\mathrm{n}}$ are required to describe the physical phenomenon of any problem of interest. Combining the variables of the form $\mathrm{x}_{1}{ }^{\mathrm{p} 1}, \mathrm{x}_{2}{ }^{\mathrm{p} 2}, \mathrm{x}_{3}{ }^{\mathrm{p} 3}, \ldots ., \mathrm{x}_{\mathrm{n}}{ }^{\mathrm{p}}$ forms several non-dimensional quantities where exponents $\mathrm{p}_{1}, \mathrm{p}_{2}, \mathrm{p}_{3}, \ldots ., \mathrm{p}_{\mathrm{n}}$ are selected to obtain a non-dimensional resultant. Assuming one of the variables $x_{i}$ has the basic dimension $x_{i}=L^{\text {ai }} T^{b i} M^{\mathrm{ci}}$, the product is expressed as $\left(\mathrm{L}^{\mathrm{a} 1} \mathrm{~T}^{\mathrm{b} 1} \mathrm{M}^{\mathrm{c} 1}\right)^{\mathrm{p} 1}$ $\left(\mathrm{L}^{\mathrm{a} 2} \mathrm{~T}^{\mathrm{b} 2} \mathrm{M}^{\mathrm{c} 2}\right)^{\mathrm{p} 2}\left(\mathrm{~L}^{\mathrm{a} 3} \mathrm{~T}^{\mathrm{b} 3} \mathrm{M}^{\mathrm{c} 3}\right)^{\mathrm{p} 3}, \ldots \ldots .,\left(\mathrm{L}^{\mathrm{an}} \mathrm{T}^{\mathrm{bn}} \mathrm{M}^{\mathrm{cn}}\right)^{\mathrm{pn}}$. The exponents of the various basic dimensions must combine to give zero value for each basic dimension, to obtain a non-dimensional product (Jha et al., 2006, 2005). Therefore, the equation below must be satisfied for this condition to be met.

for $L: \quad \mathrm{a}_{1} \mathrm{p}_{1}+\mathrm{a}_{2} \mathrm{p}_{2}+\mathrm{a}_{3} \mathrm{p}_{3}+\ldots \ldots+\mathrm{a}_{\mathrm{n}} \mathrm{p}_{\mathrm{n}}=0$

for $T: \quad b_{1} p_{1}+b_{2} p_{2}+b_{3} p_{3}+\ldots . .+b_{n} p_{n}=0$

for $M: \quad c_{1} p_{1}+c_{2} p_{2}+c_{3} p_{3}+\ldots . .+c_{n n} p_{n}=0$

These are three homogeneous equations with $n$ unknowns $\mathrm{p}_{1}, \mathrm{p}_{2}, \mathrm{p}_{3}, \ldots ., \mathrm{p}_{\mathrm{n}}$. Generally, the solutions of these equations depend on the equations' independence as well as the value of $n$, where $n$ is equal to the number of original variables in the problem. In cases where $r$ represents the rank of the matrix of coefficients, then from the theory of equations, there is k-r linearly independent solutions to Equation (1) and the number of possible independent dimensionless products is k-r. According to the Buckingham Pi Theorem, in cases where an equation involving $\mathrm{n}$ variables is dimensionally homogeneous,

$x_{1}=f\left(x_{2}, x_{3}, \ldots \ldots x_{n}\right)$

Equation (2) can be reduced to a relationship among n-r independent dimensionless products, as shown in Equation (3).

$\pi_{1}=f\left(\pi_{2}, \pi_{3}, \ldots \ldots . . \pi_{n-r}\right)$

\section{Types of similarity relations}

Basically, two types of similarity relations are used. The first type, where well-defined conditions are strictly imposed on the model design, provides the "complete similar model". Meanwhile, the second relation is derived from the first by the relaxation of certain conditions in the model design, resulting in the "distorted model".

\section{Complete Similarity}

Complete similarity exists between two systems in cases where the values of all corresponding $\pi$-factors for the prototype are equal (Equation (4)). However, complete similarity does not necessarily require geometric similarity. Therefore, two systems can appear different in shape and size, but still, be completely similar in cases where the following condition is fulfilled (David, F W \& Nolle, 1982)

$\left(\pi_{i}\right)_{\text {Prototype }}=\left(\pi_{i}\right)_{\text {Model }}$

Where $\mathrm{i}=1,2,3, \ldots \ldots \ldots . . \mathrm{n}-\mathrm{r}$.

\section{The Principle of Distortion}

In modeling practice, there are often situations where the conditions of complete similarity are impossible to achieve, and consequently, a different modeling approach is required. In dynamic analysis, fulfilling all the design conditions with only one length scale factor which is not unity, is commonly impractical. This is often due to inadequate materials, unavailability of specific member dimensions (cases of enormous length and minuscule diameter or cases where one member has enormous length and another has minute length). In these cases, two or more different length scales must be selected, and these types of models are referred to as distorted models (David, F W \& Nolle, 1982) 


\section{The Scaling Factor $\lambda$}

To achieve meaningful modeling, the rations of respective variables in similar systems must be constant. For a prototype-model relationship, this condition expresses linearity between respective variables and is defined by a non-dimensional constant of proportionality referred to as the scaling factor, $\lambda$ (Equation $(5))$.

$\lambda_{x_{i}}=\frac{\text { magnitude of variable } x_{i} \text { in prototype }}{\text { magnitude of variable } x_{i} \text { in model }}$

$\Pi$-factors contain only powers of variables, therefore, the notion of scaling factors also applies to the ratios of respective $\pi$-factors, as shown in Equation (6)).

$\lambda_{x_{i}}=\frac{\text { magnitude of } \pi_{i} \text { in prototype }}{\text { magnitude of } \pi_{i} \text { in model }}$

\section{Derivation of the scaling laws}

The drillstring dynamics are often analyzed through mass-spring-damper models. A drillstring, constrained between the rotary table and the well bottom, is commonly divided into segments, which represent mass elements of a beam. The responses of these segments to the external excitation, whether constant or periodical, are described by a second-order ordinary differential equation (ODE), known as the equation of motion. Khulief \& Al-Naser (2005) derived the equation of motion for a rotating drillstring using the Lagrangian approach, as well as the finite-element method, while Chunjie \& Tie (2009) discussed the drillstring vibration's basic equation. Therefore, the equation of motion for the drillstring is given below (Equation (7)).

$[\mathrm{M}][\ddot{\mathrm{e}}]+[\mathrm{C}][\mathrm{e}]+[\mathrm{K}][\mathrm{e}]=\{\mathrm{F}(\mathrm{t})\}$

Where $\{\mathrm{e}\},\{\ddot{e}\}$ and $\{\ddot{e}\}$ denote the displacement, velocity, and acceleration vectors, respectively, while $[\mathrm{M}]$, $[C]$, and $[K]$ represent the overall mass, damping, and stiffness matrices, respectively, and $\{\mathrm{F}(\mathrm{t})\}$ is the external force vector of the entire drill-string system. Using the conventional modal analysis Wu (2007) \& Wu et al (2002), Equation (8) is obtained.

$m_{i i} \ddot{\eta}_{i}+2 m_{i i} \xi_{i} \dot{\eta}_{i}+m_{i i} \omega_{i}^{2} \eta_{i}=f_{i}(t)$

Where, $m_{i i}$ and $\xi_{i}$ denotes the generalized mass and damping ratio for translation d.o.f motions, as well as the mass moment of inertia and damping ratio for rotational d.o.f. motions respectively. $\ddot{\eta}_{i}, \dot{\eta}_{i}$ and $\eta_{i}$ signify the acceleration, velocity, and displacement for translation d.o.f motions and angular acceleration, angular velocity, and angular displacement for rotational d.o.f motions respectively. Meanwhile, $f_{i}(t)$ represents the generalized force for translation d.o.f motions and torque for rotational d.o.f motions respectively, with each quantity corresponding to the ith mode shape $\left\{\phi_{i}\right\}$ and $i$ th natural frequency, $\omega_{i}$.

\section{Scalable Parameters}

Assuming all the symbols in Equation (8) represent the scalable physical parameters between the scale model and the full-size drillstring system (Wu et al., 2002; Wu, 2007), the parameters for dynamic analysis can be tabulated as shown below.

Table 1 . The dimensions of measured quantities for dynamic analysis

\begin{tabular}{|c|c|c|}
\hline Symbol & $\begin{array}{l}\text { Measured } \\
\text { Quantity }\end{array}$ & Dimension \\
\hline$\eta$ & $\begin{array}{l}\text { Characteristic } \\
\text { length }\end{array}$ & $\mathrm{L}$ \\
\hline$\xi$ & Damping ratio & 1 \\
\hline$\omega$ & $\begin{array}{l}\text { Natural } \\
\text { frequency }\end{array}$ & $\mathrm{T}^{-1}$ \\
\hline$m$ & Mass & M \\
\hline$t$ & $\begin{array}{l}\text { Characteristic } \\
\text { time }\end{array}$ & $\mathrm{T}$ \\
\hline$f$ & Force & $\mathrm{MLT}^{-2}$ \\
\hline
\end{tabular}




\section{Determining $\pi$-Terms}

Using the method above based on Buckingham's pi theorem, the equation below is obtained.

$\eta^{p_{1}} \xi^{p_{2}} \omega^{p_{3}} m^{p_{4}} t^{p_{5}} f^{p_{6}}=M^{0} L^{0} T^{0}$

Substituting the basic dimension for each variable in Equation (9), we obtained Equation (10) with further explanation for length, mass, and time shown in Eq. (11),(12), and (13).

$L^{p_{1}} 1^{p_{2}}\left(T^{-1}\right)^{p_{3}} M^{p_{4}} T^{p_{5}}\left(M L T^{-2}\right)^{p_{6}}=M^{0} L^{0} T^{0}$

for $L: \quad \mathrm{p}_{1}+\mathrm{p}_{6}=0$

for $M: \quad \mathrm{p}_{4}+\mathrm{p}_{6}=0$

for $T: \quad-p_{3}+p_{5}-2 p_{6}=0$

Therefore, the dimensional matrix is:

\begin{tabular}{lcccccc}
\hline & $\boldsymbol{t}$ & $\boldsymbol{\omega}$ & $\boldsymbol{\xi}$ & $\boldsymbol{m}$ & $\boldsymbol{\eta}$ & $\boldsymbol{f}$ \\
$\mathrm{M}$ & 0 & 0 & 0 & 1 & 0 & 1 \\
$\mathrm{~L}$ & 0 & 0 & 0 & 0 & 1 & 1 \\
$\mathrm{~T}$ & 1 & -1 & 0 & 0 & 0 & -2 \\
\hline
\end{tabular}

Considering the determinant formed by the last three columns of the dimensional matrix,

$$
\left|\begin{array}{ccc}
1 & 0 & 1 \\
0 & 1 & 1 \\
0 & 0 & -2
\end{array}\right|=-2
$$

The rank of the dimensional matrix is 3 because this determinant is non-zero. Based on Buckingham's pi theorem there are $6-3=3$ dimensionless products required to describe the problem. Choosing three parameters, $\mathrm{p}_{2}, \mathrm{p}_{4}$ and $\mathrm{p}_{6}$ are expressed in terms of $\mathrm{p}_{2}, \mathrm{p}_{1}$, and $\mathrm{p}_{3}$ as shown in Equation (14).

$\left(\frac{\eta m}{t^{2} f}\right)^{p_{1}} \xi^{p_{2}}(\omega t)^{p_{3}}=M^{0} L^{0} T^{0}$

Finally, the $\pi$-terms are expressed as shown in Equation (15).

$$
\pi_{1}=\frac{\eta m}{t^{2} f} \quad \pi_{2}=\xi \quad \pi_{3}=\omega t
$$

\section{Determining Scaling laws}

The modeling or scaling laws are developed by applying similarity conditions on the pi numbers above. To determine the similarity between the prototype and model, both systems are assumed to be described by the Equation (16) and Equation (17).

Prototype: $\quad F_{p}\left(\pi_{1 p}, \pi_{1 p}, \pi_{1 p}\right)=0$

Model: $\quad F_{m}\left(\pi_{1 m}, \pi_{1 m}, \pi_{1 m}\right)=0$

Applying similarity conditions, the following statements are obtained

$\pi_{1 p}=\pi_{1 m}, \quad \pi_{2 p}=\pi_{2 m}$ and $\pi_{3 p}=\pi_{3 m}$

Subsequently, the scale factors are extracted from Equation (18) as shown below.

$$
\begin{array}{cl}
\text { I. } & \pi_{1 p}=\pi_{1 m} \Rightarrow\left(\frac{\eta m}{t^{2} f}\right)_{p}=\left(\frac{\eta m}{t^{2} f}\right)_{m} \\
& \Rightarrow \lambda_{\eta} \lambda_{m}=\lambda_{t}{ }^{2} \lambda_{f} \\
\text { II. } & \pi_{2 p}=\pi_{2 m} \Rightarrow \xi_{p}=\xi_{m} \\
& \Rightarrow \lambda_{\xi}=1 \\
\text { III. } & \pi_{3 p}=\pi_{3 m} \Rightarrow \omega t_{p}=\omega t_{m} \\
& \Rightarrow \lambda_{\omega} \lambda_{t}=1
\end{array}
$$


$\lambda_{\eta} \lambda_{m}=\lambda_{t}^{2} \lambda_{f}, \lambda_{\xi}=1, \lambda_{\omega} \lambda_{t}=1$

Where $\lambda_{\eta}, \lambda_{m}, \lambda_{\xi}, \lambda_{f}, \lambda_{t}$ and $\lambda_{\omega}$ represent the scaling factors for the generalized modal displacement, the mass, the damping ratio, the force, the time, and natural frequency.

Equation (19) indicates the requirement for the similitude between the full-size drillstring system, as well as the scale model, and is referred to as the scaling law in this article.

\section{Modes of drillstring vibrations}

Drillstring vibrations are divided into three modes: axial, torsional, and lateral (Figure 1). These three vibrations are coupled to an extent and may occur during rotary drilling. The natural frequency scaling factor of each mode is the main scaling factor for the modeling of drillstring vibrations, and depends on the drillstring's materials and geometry. For the axial and torsional modes, the natural frequency scaling factor depends on the drillstring's length and material property. Meanwhile, the lateral modes counterpart depends on the drillstring material property, length, and diameter.

Using the equation of natural frequency for three different modes from Rao (2011), the natural frequency scaling factors are shown in Eq. (20) to Eq. (22).

Transverse modes

$$
\lambda_{\omega}=\sqrt{\frac{\lambda_{k}}{\lambda_{m}}} \Rightarrow \lambda_{\omega}=\sqrt{\frac{\lambda_{E} \lambda_{I}}{\lambda_{\rho} \lambda_{A} \lambda_{l}{ }^{4}}}
$$

Axial modes

$$
\lambda_{\omega}=\sqrt{\frac{\lambda_{k}}{\lambda_{m}}} \Rightarrow \lambda_{\omega}=\sqrt{\frac{\lambda_{E}}{\lambda_{\rho} \lambda_{l}^{2}}}
$$

Torsional modes

$$
\lambda_{\omega}=\sqrt{\frac{\lambda_{k_{t}}}{\lambda_{J_{0}}}} \Rightarrow \lambda_{\omega}=\sqrt{\frac{\lambda_{G} \lambda_{I}}{\lambda_{J_{0}} \lambda_{l}}}
$$

Where, $\lambda_{k}, \lambda_{E}, \lambda_{I}, \lambda_{\rho}, \lambda_{A}, \lambda_{G}$ and $\lambda_{J_{0}}$ are scaling factors for the stiffness, modulus of elasticity, area moment of inertia, density, modulus of rigidity, and mass moment of inertia.

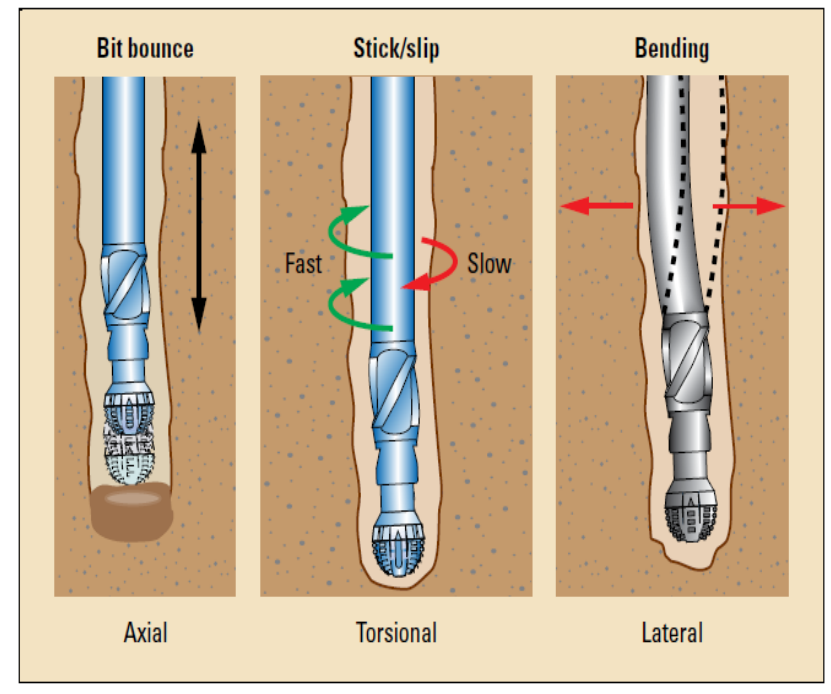

Figure 1. The different modes of drillstring vibrations (adopted from Jardine et al. (1994)).

\section{Scaling factors between the full-size drillstring system and scale model}

Using geometry similarity, meaning the same length scale factor for both length and diameter of the drillstring system, the following Equation (23) is obtained.

$$
\lambda_{l}=\lambda_{d}=\lambda_{\eta}
$$

And for similar materials, Equation (24): 
$\lambda_{E}=\lambda_{G}=\lambda_{\rho}=1$

Tables 2 to 4 show all scale factors for the three modes of drillstring vibrations.

Table 2. List of all scale factors for Lateral modes

\begin{tabular}{|c|c|c|}
\hline $\begin{array}{l}\text { Description of scale } \\
\text { factor }\end{array}$ & Calculation & Result \\
\hline Natural Frequency, $\lambda_{\omega}$ & $\sqrt{\frac{\lambda_{E} \lambda_{I}}{\lambda_{\rho} \lambda_{A} \lambda_{l}{ }^{4}}}=\sqrt{\frac{\lambda_{\eta}{ }^{4}}{\lambda_{\eta}{ }^{2} \lambda_{\eta}{ }^{4}}}$ & $\frac{1}{\lambda_{\eta}}$ \\
\hline $\begin{array}{l}\text { Area moment of } \\
\text { inertia, } \boldsymbol{\lambda}_{\mathbf{I}}\end{array}$ & $\lambda_{d}^{4}$ & $\lambda_{\eta}^{4}$ \\
\hline Time, $\lambda_{\mathrm{t}}$ & $\frac{1}{\lambda_{\omega}}$ & $\lambda_{\eta}$ \\
\hline Mass, $\boldsymbol{\lambda}_{\mathbf{m}}$ & $\lambda_{\rho} \lambda_{A} \lambda_{l}=\lambda_{\eta}^{2} \lambda_{\eta}$ & $\lambda_{\eta}{ }^{3}$ \\
\hline Displacement, $\boldsymbol{\lambda}_{\boldsymbol{\eta}}$ & $\lambda_{\eta}$ & $\lambda_{\eta}$ \\
\hline Force, $\boldsymbol{\lambda}_{\mathbf{f}}$ & Using eqn (19) & $\lambda_{\eta}{ }^{2}$ \\
\hline Stiffness, $\boldsymbol{\lambda}_{\mathbf{k}}$ & $\lambda_{m} \lambda_{\omega}^{2}$ & $\lambda_{\eta}$ \\
\hline Damping Const., $\boldsymbol{\lambda}_{\mathbf{c}}$ & $\lambda_{\xi} \lambda_{m} \lambda_{\omega}$ & $\lambda_{\eta}{ }^{2}$ \\
\hline Rotating Speed, $\lambda_{\Omega}$ & $\frac{\lambda_{\theta}}{\lambda_{t}}$ & $\frac{1}{\lambda_{\eta}}$ \\
\hline
\end{tabular}

The three modes of drillstring vibrations are coupled to an extent. In addition, bit whirl is commonly triggered by the high bit speeds during stick-slip motion, which tends to generate lateral vibration of the BHA as the bit accelerates during the slip phase. Enormous lateral vibration of the BHA into the wellbore often causes bit-bounce due to axial shortening, and Induced axial vibrations at the bit can lead to lateral vibrations in the BHA. Also, the axial and torsional vibrations observed at the rig floor are sometimes related to severe lateral vibrations downhole near the bit. The axial force scale factor, $\lambda_{\boldsymbol{f}}$, depends on the lateral natural frequency scale factor for the drillstring system, and is derived using the equation below.

Equation of transverse natural frequency for drillstring system (Rao, 2011).

$$
\begin{aligned}
& \omega_{n}=\left(\frac{\pi^{2}}{L^{2}}\right)\left\{\left(\frac{E I}{\rho A}\right)\left(n^{4}-n^{2}\left(\frac{f}{f_{c r}}\right)\right)\right\}^{1 / 2} \\
& \Rightarrow \omega_{n}{ }^{2}=\left(\frac{\pi^{2}}{L^{2}}\right)\left\{\left(\frac{E I}{\rho A}\right)\left(n^{4}-n^{2}\left(\frac{f}{f_{c r}}\right)\right)\right\} \\
& \Rightarrow \omega_{n}{ }^{2}=n^{4} \pi^{4}\left(\frac{E I}{\rho A L^{4}}\right)-n^{2} \pi^{2}\left(\frac{f}{\rho A L^{2}}\right)
\end{aligned}
$$

For model drill-string:

$\omega_{n_{m}}^{2}=n^{4} \pi^{4}\left(\frac{E_{m} I_{m}}{\rho_{m} A_{m} L_{m}{ }^{4}}\right)-n^{2} \pi^{2}\left(\frac{f_{m}}{\rho_{m} A_{m} L_{m}{ }^{2}}\right)$

For full-scale drill-string:

$\omega_{n_{f}}{ }^{2}=n^{4} \pi^{4}\left(\frac{E_{f} I_{f}}{\rho_{f} A_{f} L_{f}{ }^{4}}\right)-n^{2} \pi^{2}\left(\frac{f_{m}}{\rho_{m} A_{m} L_{m}{ }^{2}}\right)$

Dividing Eq. (26) by Eq. (25), Eq. (27) is formed.

$\lambda_{\omega}^{2}=\lambda_{E} \lambda_{I} / \lambda_{\rho} \lambda_{A} \lambda_{L}^{2}=\lambda_{f} / \lambda_{\rho} \lambda_{A} \lambda_{L}^{2}$

$\Rightarrow\left(\lambda_{E} \lambda_{I}\right) / \lambda_{\rho} \lambda_{A} \lambda_{L}^{2} \lambda_{\omega}^{2}=\lambda_{f} / \lambda_{\rho} \lambda_{A} \lambda_{L}^{2} \lambda_{\omega}^{2}=1$

$\Rightarrow \lambda_{I} / \lambda_{A} \lambda_{l}^{2} \lambda_{\omega}^{2}=\lambda_{f} / \lambda_{A} \lambda_{l}^{2} \lambda_{\omega}^{2}=1$

$$
\lambda_{\omega}=\frac{1}{\lambda_{\eta}}, \quad \lambda_{f}=\lambda_{\eta}^{2}
$$


Table 3. List of all scale factors for Axial modes

\begin{tabular}{lcc}
\hline $\begin{array}{l}\text { Description of } \\
\text { scale factor }\end{array}$ & Calculation & Result \\
\hline $\begin{array}{l}\text { Natural } \\
\text { Frequency, } \lambda_{\omega}\end{array}$ & $\sqrt{\frac{\lambda_{E}}{\lambda_{\rho} \lambda_{l}{ }^{2}}}=\sqrt{\frac{1}{\lambda_{\boldsymbol{\eta}}{ }^{2}}}$ & $\frac{1}{\lambda_{\boldsymbol{\eta}}}$ \\
Time, $\lambda_{\mathbf{t}}$ & $\frac{1}{\lambda_{\omega}}$ & $\lambda_{\boldsymbol{\eta}}$ \\
Mass, $\lambda_{\mathbf{m}}$ & $\lambda_{\rho} \lambda_{A} \lambda_{l}=\lambda_{\boldsymbol{\eta}}{ }^{2} \lambda_{\boldsymbol{\eta}}$ & $\lambda_{\boldsymbol{\eta}}{ }^{3}$ \\
Displacement, $\lambda_{\boldsymbol{\eta}}$ & $\lambda_{\boldsymbol{\eta}}$ & $\lambda_{\boldsymbol{\eta}}$ \\
Force, $\lambda_{\mathbf{f}}$ & $\lambda_{\boldsymbol{m}} \lambda_{\boldsymbol{g}}=\lambda_{\boldsymbol{\eta}}{ }^{3} \cdot 1$ & $\lambda_{\boldsymbol{\eta}}{ }^{3}$ \\
Stiffness, $\lambda_{\mathrm{k}}$ & $\lambda_{\boldsymbol{m}} \lambda_{\omega}{ }^{2}$ & $\lambda_{\boldsymbol{\eta}}$ \\
$\begin{array}{l}\text { Damping Const., } \\
\lambda_{\mathbf{c}}\end{array}$ & $\lambda_{\xi} \lambda_{m} \lambda_{\omega}$ & $\lambda_{\boldsymbol{\eta}}{ }^{2}$ \\
Rotating Speed, & $\frac{\lambda_{\boldsymbol{\theta}}}{\lambda_{\Omega}}$ & $\frac{1}{\lambda_{\boldsymbol{\eta}}}$ \\
\hline
\end{tabular}

Table 4. List of all scale factors for Torsional modes

\begin{tabular}{|c|c|c|}
\hline $\begin{array}{l}\text { Description of } \\
\text { scale factor }\end{array}$ & Calculation & Result \\
\hline $\begin{array}{l}\text { Natural } \\
\text { Frequency, } \lambda_{\omega}\end{array}$ & $\sqrt{\frac{\lambda_{G} \lambda_{I}}{\lambda_{J_{0}} \lambda_{l}}}=\sqrt{\frac{\lambda_{\eta}{ }^{4}}{\lambda_{\eta}{ }^{3} \lambda_{\eta}{ }^{2} \lambda_{\eta}}}$ & $\frac{1}{\lambda_{\eta}}$ \\
\hline Time, $\lambda_{t}$ & $\frac{1}{\lambda_{\omega}}$ & $\lambda_{\eta}$ \\
\hline $\begin{array}{l}\text { Mass moment of } \\
\text { inertia, } \lambda_{J_{0}}\end{array}$ & $\lambda_{m} \lambda_{d}{ }^{2}=\lambda_{\boldsymbol{\eta}}{ }^{3} \lambda_{\boldsymbol{\eta}}{ }^{2}$ & $\lambda_{\eta}{ }^{5}$ \\
\hline $\begin{array}{l}\text { Area moment of } \\
\text { inertia, } \lambda_{I}\end{array}$ & $\lambda_{d}^{4}$ & $\lambda_{\eta}^{4}$ \\
\hline $\begin{array}{l}\text { Angular } \\
\text { displacement, } \lambda_{\theta}\end{array}$ & 1 & 1 \\
\hline Torque, $\lambda_{\mathrm{T}}$ & Using eq $q^{n}$ (19) & $\lambda_{\eta}^{3}$ \\
\hline Stiffness, $\lambda_{k}$ & $\lambda_{J_{0}} \lambda_{\omega}^{2}$ & $\lambda_{\eta}^{3}$ \\
\hline $\begin{array}{l}\text { Damping Const., } \\
\lambda_{c}\end{array}$ & $\lambda_{\xi} \lambda_{J_{0}} \lambda_{\omega}$ & $\lambda_{\eta}{ }^{4}$ \\
\hline $\begin{array}{l}\text { Rotating Speed, } \\
\lambda_{\Omega}\end{array}$ & $\frac{\lambda_{\theta}}{\lambda_{t}}$ & $\frac{1}{\lambda_{\eta}}$ \\
\hline
\end{tabular}

Difficulties to construct a drillstring scale model

The scale factors above have been used to construct a 5-m length drill pipe scaled model. For the case of the $1200 \mathrm{~m}$ length actual drill pipe is shown by Eq. (28).

$\lambda_{l}=\lambda_{\boldsymbol{\eta}}=\frac{l_{\text {full }}}{l_{\text {model }}}=\frac{1200}{5}=240$ 
Table 5. The physical parameters of the full scale (prototype) and model drillstring

\begin{tabular}{|c|c|c|}
\hline Parameters & Prototype & Model \\
\hline Drill pipe length, $l_{\mathrm{p}}$ & $1200 \mathrm{~m}$ & $5 \mathrm{~m}$ \\
\hline Drill pipe O.D., $\mathrm{d}_{\mathrm{o}}$ & $127 \mathrm{~mm}$ & $0.53 \mathrm{~mm}$ \\
\hline Drill pipe I.D., $\mathrm{d}_{\mathrm{i}}$ & $108.6 \mathrm{~mm}$ & $0.4525 \mathrm{~mm}$ \\
\hline Drill collar length, $\mathrm{l}_{\mathrm{c}}$ & $200 \mathrm{~m}$ & $0.83 \mathrm{~m}$ \\
\hline Drill collar O.D., $\mathrm{d}_{\mathrm{o}}$ & $203.2 \mathrm{~mm}$ & $0.847 \mathrm{~mm}$ \\
\hline Drill collar I.D., $\mathrm{d}_{\mathrm{i}}$ & $76.2 \mathrm{~mm}$ & $0.3175 \mathrm{~mm}$ \\
\hline $\begin{array}{l}\text { Bore hole diameter, } \\
d_{h}\end{array}$ & $317.5 \mathrm{~mm}$ & $1.323 \mathrm{~mm}$ \\
\hline $\begin{array}{l}\text { Drillstring Rotation, } \\
\Omega\end{array}$ & $150 \mathrm{rpm}$ & $36000 \mathrm{rpm}$ \\
\hline
\end{tabular}

Table 5 summarizes the conversions between the prototype and the model parameters. In cases where the laboratory permits a longer drillstring, the model's necessary parameters are recalculated using the derived scale factors. A major limitation of the derived scaling factors for the case of geometric similarity condition is the model thickness which is often too thin to be built in the lab. Adequate drill pipe thickness is obtained by increasing the scaling factor, however, this produces a longer drillstring model, but every laboratory has a limitation in length to manage space for the construction of a drillstring model. The scaled parameters for the model provide a very high-speed rotation at the top, but this limitation is overcome by the selection of the devices and designing a safer high rotational experimental lab setup. In the next section, a geometrical distorted model is discussed to achieve the experimentally designable drillstring model thickness.

\section{Geometrical distorted scale model technique}

This technique is based on generating geometrical distortions on scale models and, optionally, also in boundary conditions for compensating certain changes in physical laws across these distortions. The technique has no geometrical restrictions and allows the model's geometrical characteristics to be altered, thus obtaining a distorted scale model. In this section, the geometrically distorted model is derived for achieving the required scale model thickness. First, the geometry similarity is applied, then a modified scale factor $C_{D}$ is used to obtain the drillstring's diameter (Equation (31)). Tables 6 and 7 show a summary of the scale factors derived for the three different modes of vibrations.

$\lambda_{l}=\lambda_{\boldsymbol{\eta}}, \quad \lambda_{d}=\lambda_{\boldsymbol{\eta}} * C_{D}$

And for similar material by Equation (32),

$\lambda_{E}=\lambda_{G}=\lambda_{\rho}=1$

Table 6. The scale factors for transverse and axial modes

\begin{tabular}{llc}
\hline $\begin{array}{l}\text { Description of scale } \\
\text { factor }\end{array}$ & $\begin{array}{l}\text { Transverse } \\
\text { modes }\end{array}$ & Axial modes \\
\hline Natural Frequency, $\lambda_{\omega}$ & $\frac{C_{D}}{\lambda_{\eta}}$ & $\frac{1}{\lambda_{\eta}}$ \\
Time, $\lambda_{t}$ & $\frac{\lambda_{\eta}}{C_{D}}$ & $\lambda_{\eta}$ \\
Mass, $\lambda_{\mathbf{m}}$ & $\lambda_{\eta}{ }^{3} * C_{D}{ }^{2}$ & $\lambda_{\eta}{ }^{3} * C_{D}{ }^{2}$ \\
Displacement, $\lambda_{\boldsymbol{\eta}}$ & $\frac{\lambda_{\eta}}{C_{D}}$ & $\lambda_{\eta}$ \\
Force, $\lambda_{\mathbf{f}}$ & $\lambda_{\eta}{ }^{2} * C_{D}{ }^{3}$ & $\lambda_{\eta}{ }^{3} * C_{D}{ }^{3}$ \\
Stiffness, $\lambda_{\mathbf{k}}$ & $\lambda_{\eta} * C_{D}{ }^{4}$ & $\lambda_{\eta} * C_{D}{ }^{2}$ \\
\hline
\end{tabular}




\begin{tabular}{lll}
\hline Damping Const., $\lambda_{\mathbf{c}}$ & $\lambda_{\boldsymbol{\eta}}{ }^{2} * \mathrm{C}_{\mathrm{D}}{ }^{3}$ & $\lambda_{\boldsymbol{\eta}}{ }^{2} * \mathrm{C}_{\mathrm{D}}{ }^{2}$ \\
Rotating Speed, $\lambda_{\Omega}$ & $\frac{\mathrm{C}_{\mathrm{D}}}{\lambda_{\boldsymbol{\eta}}}$ & $\frac{1}{\lambda_{\boldsymbol{\eta}}}$
\end{tabular}

The scaling factor of axial forces (f) for lateral vibration is shown by Eq. (33).

$\lambda_{\omega}=C_{D} / \lambda_{\eta} \quad \lambda_{f}=C_{D}^{4} * \lambda_{\eta}^{2}$

Table 7. List of all the scale factors for torsional modes

\begin{tabular}{ll}
\hline Description of scale factor & Results \\
\hline Natural Frequency, $\lambda_{\boldsymbol{\omega}}$ & $\frac{1}{\lambda_{\boldsymbol{\eta}}}$ \\
Time, $\lambda_{\mathbf{t}}$ & $\lambda_{\boldsymbol{\eta}}$ \\
Mass moment of inertia, $\lambda_{\mathbf{I}_{\mathbf{0}}}$ & $\lambda_{\boldsymbol{\eta}}{ }^{5} * \mathrm{C}_{\mathrm{D}}{ }^{4}$ \\
Area moment of inertia, $\lambda_{\mathbf{I}}$ & $\lambda_{\boldsymbol{\eta}}{ }^{4} * \mathrm{C}_{\mathrm{D}}{ }^{4}$ \\
Angular displacement, $\lambda_{\boldsymbol{\theta}}$ & 1 \\
Torque, $\lambda_{\mathbf{T}}$ & $\lambda_{\boldsymbol{\eta}}{ }^{3} * \mathrm{C}_{\mathrm{D}}{ }^{2}$ \\
Stiffness, $\lambda_{\mathbf{k}}$ & $\lambda_{\boldsymbol{\eta}}{ }^{3} * \mathrm{C}_{\mathrm{D}}{ }^{4}$ \\
Damping Const., $\lambda_{\mathbf{c}}$ & $\lambda_{\boldsymbol{\eta}}{ }^{4} * \mathrm{C}_{\mathrm{D}}{ }^{4}$ \\
Rotating Speed, $\lambda_{\Omega}$ & $\frac{1}{\lambda_{\boldsymbol{\eta}}}$ \\
\hline
\end{tabular}

Table 8 . The physical parameters of the full scale (prototype) and model drillstring for the modified scaling factor $\mathrm{C}_{\mathrm{D}}=0.1 \& \lambda_{l}=\lambda_{\boldsymbol{\eta}}=240$.

\begin{tabular}{lll}
\hline Parameters & Prototype & Model \\
\hline Drill pipe length, $\mathrm{l}_{\mathrm{p}}$ & $1200 \mathrm{~m}$ & $5 \mathrm{~m}$ \\
Drill pipe O.D., $\mathrm{d}_{\mathrm{o}}$ & $127 \mathrm{~mm}$ & $5.3 \mathrm{~mm}$ \\
Drill pipe I.D., $\mathrm{d}_{\mathrm{i}}$ & $108.6 \mathrm{~mm}$ & $4.525 \mathrm{~mm}$ \\
Drill collar length, $\mathrm{l}_{\mathrm{c}}$ & $200 \mathrm{~m}$ & $0.83 \mathrm{~m}$ \\
Drill collar O.D., $\mathrm{d}_{\mathrm{o}}$ & $203.2 \mathrm{~mm}$ & $8.47 \mathrm{~mm}$ \\
Drill collar I.D., $\mathrm{d}_{\mathrm{i}}$ & $76.2 \mathrm{~mm}$ & $3.175 \mathrm{~mm}$ \\
Bore hole diameter, $\mathrm{d}_{\mathrm{h}}$ & $317.5 \mathrm{~mm}$ & $13.23 \mathrm{~mm}$ \\
Hook load, Fh & $550000 \mathrm{~N}$ & $3.9785 \mathrm{~N}$ \\
Drillstring Rotation, $\Omega$ & $150 \mathrm{rpm}$ & $36000 \mathrm{rpm}$ \\
\hline
\end{tabular}

A sufficient thickness of the scaled drillstring was obtained using the modified scaling factor $\mathrm{C}_{\mathrm{D}}$. However, this provides a different scaling factor of the lateral natural frequency, compared to the axial and torsional counterparts. Therefore, the modified scaling factor method is applicable for axial and torsional modes of drillstring dynamics but not for the lateral mode. In the actual application, a set of stabilizers are used in the downhole to minimize the lateral vibrations, therefore, the modified scaling factor is an effective way 
to construct a laboratory scaled drillstring set up to analyze the coupled axial and torsional vibrations. The next section presents a validation of the scaling laws for geometrically distorted scale models of a vertical drillstring.

\section{Validation of the scaling laws for geometrically distorted scale models of a vertical drillstring}

Figure 2 shows the schematics of the drillstring considered for validating the scaling laws using numerical analysis. The dynamic models used in the numerical analysis employed an energy-based method, Bond Graph Theory, which is a unified dynamic system representation language where the connections between multi-disciplinary elements are seamlessly and explicitly represented by power flows. In the vector form, concise descriptions of complex systems are provided. Appendix a presents an overview of the bond graph approach. A lumped-segment approach is used to model the drillstring axial and torsional dynamics. In this approach, the system is divided into a series of inertias, interconnected with compliances (Wu, 2007). The model's accuracy depends on the number of elements considered; however, in contrast to a modal expansion approach, there is no need to determine the analytical model shapes and natural frequencies. Furthermore, more accurate results are obtained in cases where a system model is divided into a larger number of elements. The behavior approaches a continuous system as the number of segments approaches infinity.

A total of 13 segments were used in the axial and torsional dynamic models to capture the first eight axial natural frequencies of the whole drillstring, with 10 segments used for the long drill pipe and three segments for the relatively short drill collar. Figure 3 shows the lumped segments bond graph models for the axial and torsional motions of a drillstring. The axial segment bond graph model shows a mass (element I) and gravity force source (element Se) associated with the segment velocity, v. Furthermore, the segment's axial compliance and material damping are modeled by parallel compliance $(\mathrm{C})$ and dissipative elements, the forces of which are functions of the segment's relative velocity (calculated by the 0 -junction) concerning the adjoining segment. In the case of vertical drilling, the buoyancy weight of the drillstring segments acts in the longitudinal direction.

Rather than a computationally intensive and difficult-to-parameterize complete dynamic representation, a quasi-static rock-bit model, which provides coupling between axial and torsional drillstring dynamics, was used. The model equations are based on the bit-rock model in YIGIT \& CHRISTOFOROU (2000); Ahmet S. Yigit \& Christoforou (2006), and are discussed in M. Sarker \& Rideout (2012). Appendix B presents the bond graph model of the rotary drillstring. Please refer to Karnopp et al., (2012) and M. M. Sarker, (2012) for more details on the bond graph modeling method.

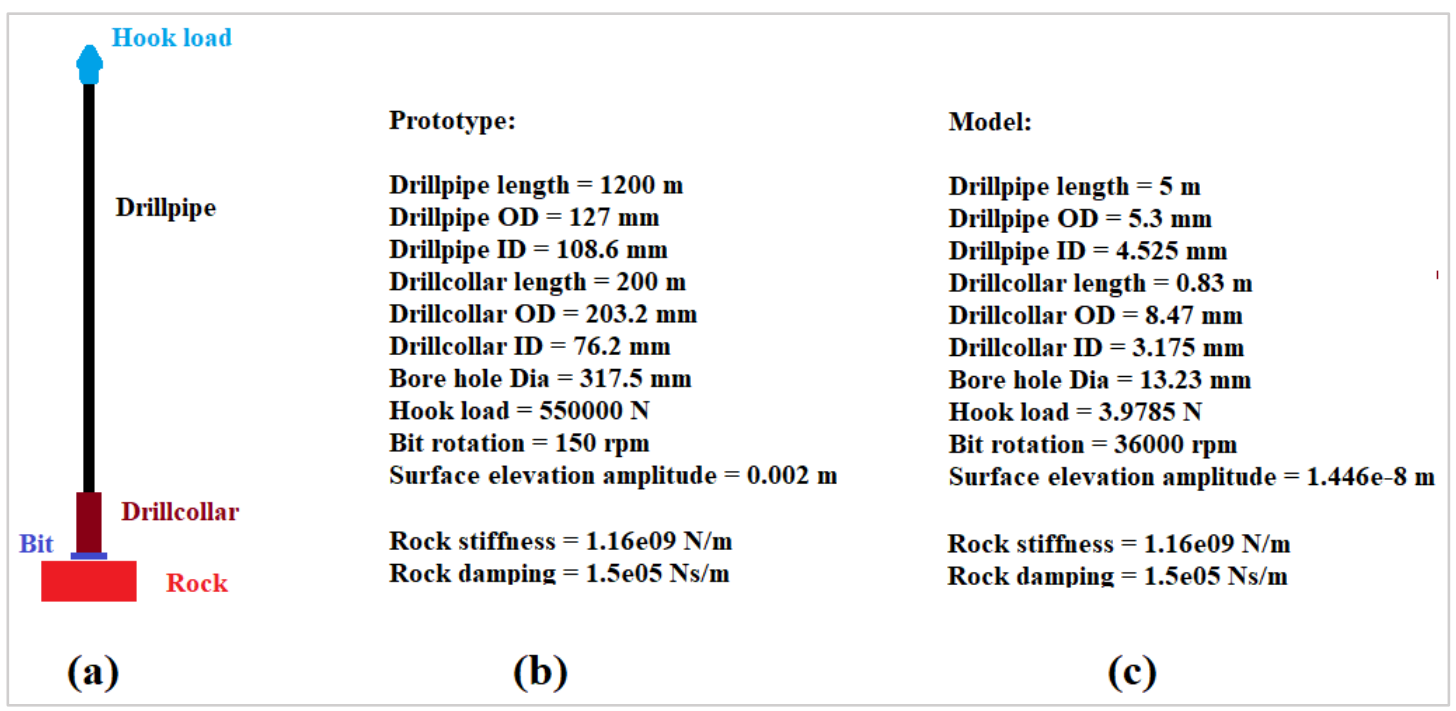

Figure 2. The drillstring model validation (a) schematics, (b) prototype dimensions and (c) model dimensions 


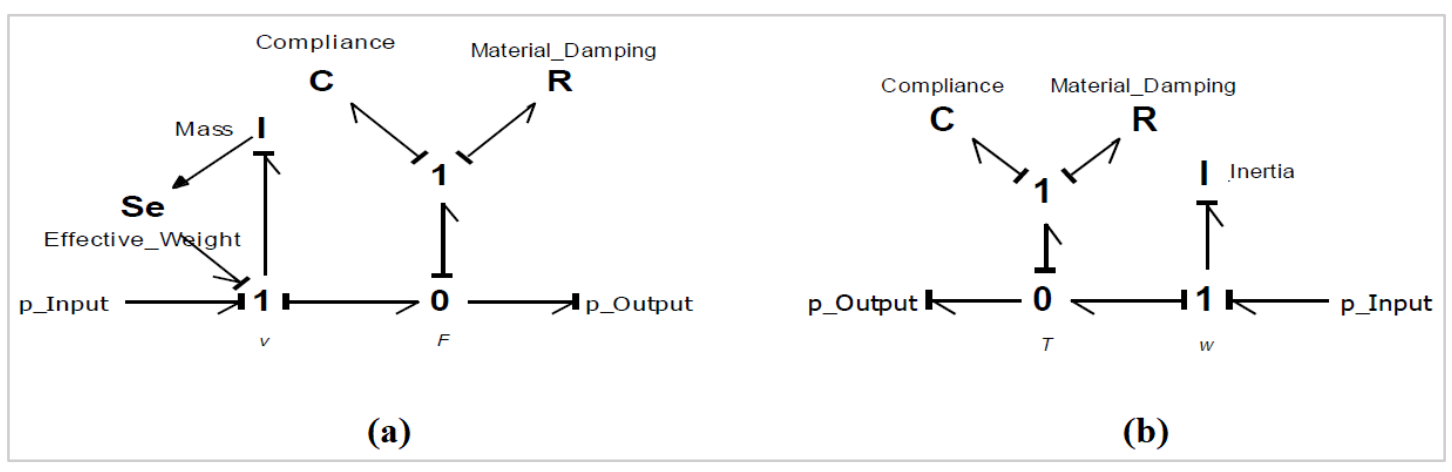

Figure 3. The drillstring bond graph model (a) axial dynamics and (b) torsional dynamics.

\section{RESULTS}

The numerical simulations above are aimed at validating the scaling laws for axial and torsional dynamics. Furthermore, the frequency domain toolbox in the $20 \mathrm{Sim}^{\circledR}$ is able to extract the axial and torsional natural frequencies from the model outputs. Based on Table 9, the predictive natural frequencies from the scaled model drillstring accurately match with the natural frequencies of the prototype drillstring. Therefore, the geometrically distorted scaling method is a potential highly effective implication to capture the axial and torsional dynamics of a prototype drillstring from the laboratory scaled drillstring model. The validation also includes a comparison of the dynamic axial forces in the drillstring. The dynamic weight on bit plots (Figure 4) shows the scaled drillstring model is able to accurately predict the frequency of the forced vibrations of the prototype drillstring. However, the predictive amplitude of the axial force from the scaled model is lower, compared to the measurement of the prototype. The plots of the axial forces in the drillstring segments (Figures 5-8) show the scaled model is able to accurately predict the frequencies of the prototype drillstring's forced vibrations. In addition, the scaled model is also able to accurately predict the amplitude of the axial forces at the top of the prototype drillstring. However, the differences are only evident in cases where a comparison study is conducted close to the bit and the collar portions. The modeling and simulation software used for this simulation allows for graphical modeling, similar to drawing an engineering scheme. Furthermore, the software has the capacity to simulate and analyze the behavior of multi-domain dynamic systems. The software platform enables the C-code to be generated and this code on hardware for rapid prototyping and HIL-simulation. Therefore, this study's results are a potential effective tool for designing a laboratory-scale drilling set-up. The scaling laws generated can be coded with the scaled drilling set-up to present the field drilling system results in real-time.

Table 9. Validation of the scaling factors of the natural frequency

\begin{tabular}{lllll}
\hline \multirow{2}{*}{$\begin{array}{l}\text { No of } \\
\text { Modes }\end{array}$} & \multicolumn{2}{l}{ Axial Natural Frequencies (rad/sec) } & \multicolumn{2}{l}{ Torsional Natural Frequencies (rad/sec) } \\
\cline { 2 - 5 } & $\begin{array}{l}\text { Prototype } \\
\text { measurements }\end{array}$ & $\begin{array}{l}\text { Model prediction (using } \\
\text { scaling laws) }\end{array}$ & $\begin{array}{l}\text { Prototype } \\
\text { measurements }\end{array}$ & $\begin{array}{l}\text { Model prediction } \\
\text { (using scaling laws) }\end{array}$ \\
\hline $\mathbf{1}$ & 6.32 & 6.33 & 1.64 & 1.64 \\
$\mathbf{2}$ & 18.76 & 18.75 & 8.64 & 8.65 \\
$\mathbf{3}$ & 30.22 & 30.05 & 16.56 & 16.56 \\
$\mathbf{4}$ & 36.24 & 36.38 & 24.18 & 24.18 \\
$\mathbf{5}$ & 44.03 & 44.13 & 31.24 & 31.24 \\
$\mathbf{6}$ & 54.19 & 54.21 & 37.54 & 37.54 \\
$\mathbf{7}$ & 63.47 & 63.46 & 42.9 & 42.91 \\
$\mathbf{8}$ & 71.44 & 71.42 & 47.07 & 47.08 \\
\hline
\end{tabular}




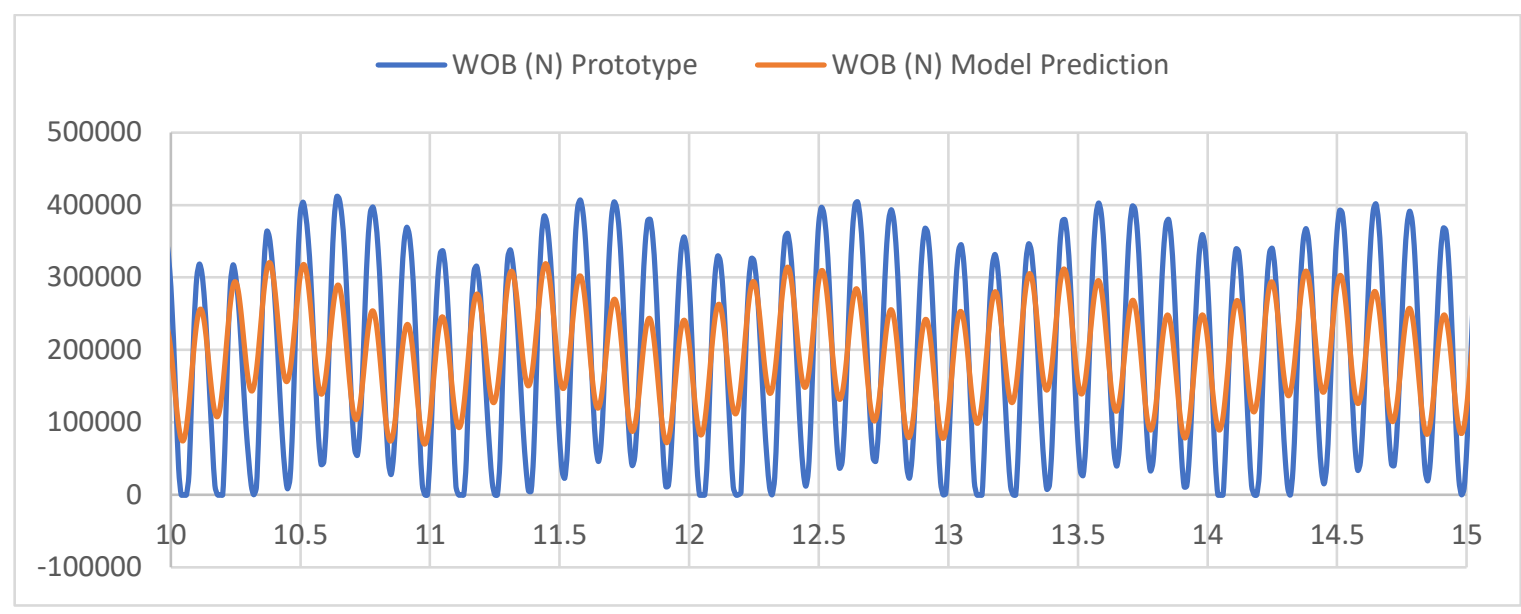

Figure 4. The dynamic weight on bit (WOB) comparison plots.

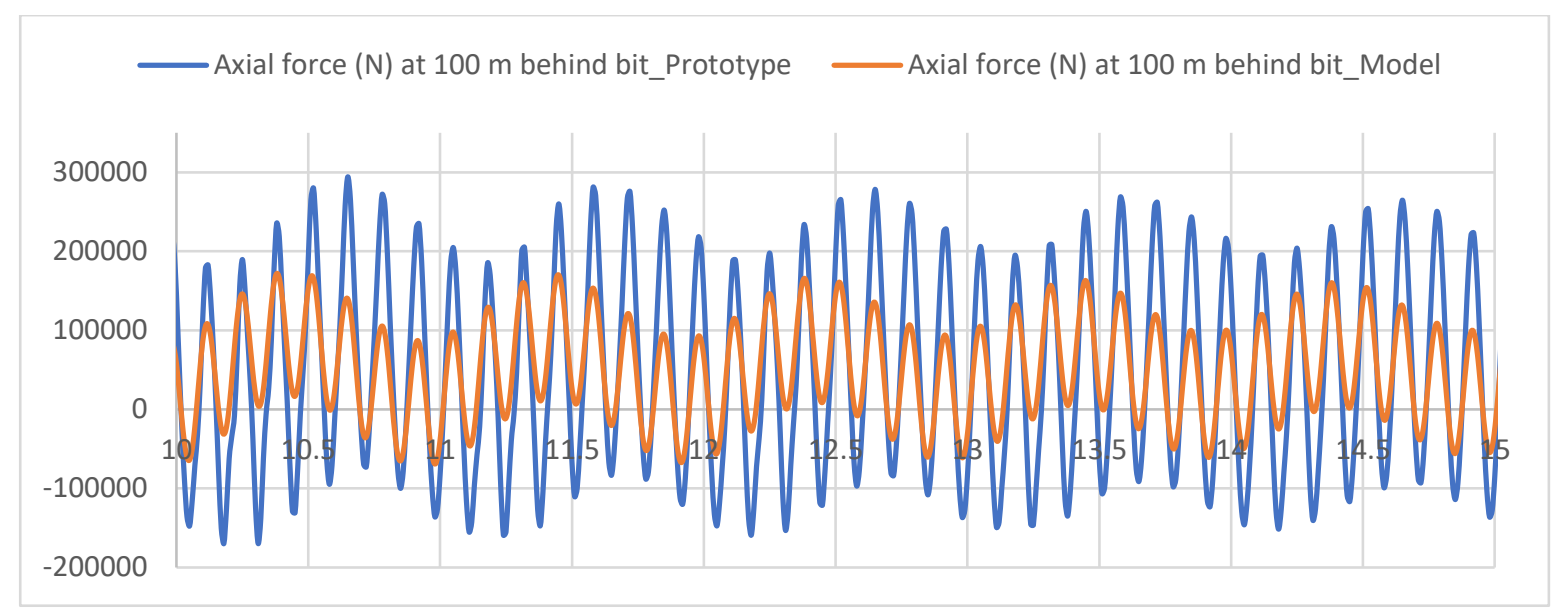

Figure 5. Comparison plots of the axial force at 100-m behind the bit (collar segment)

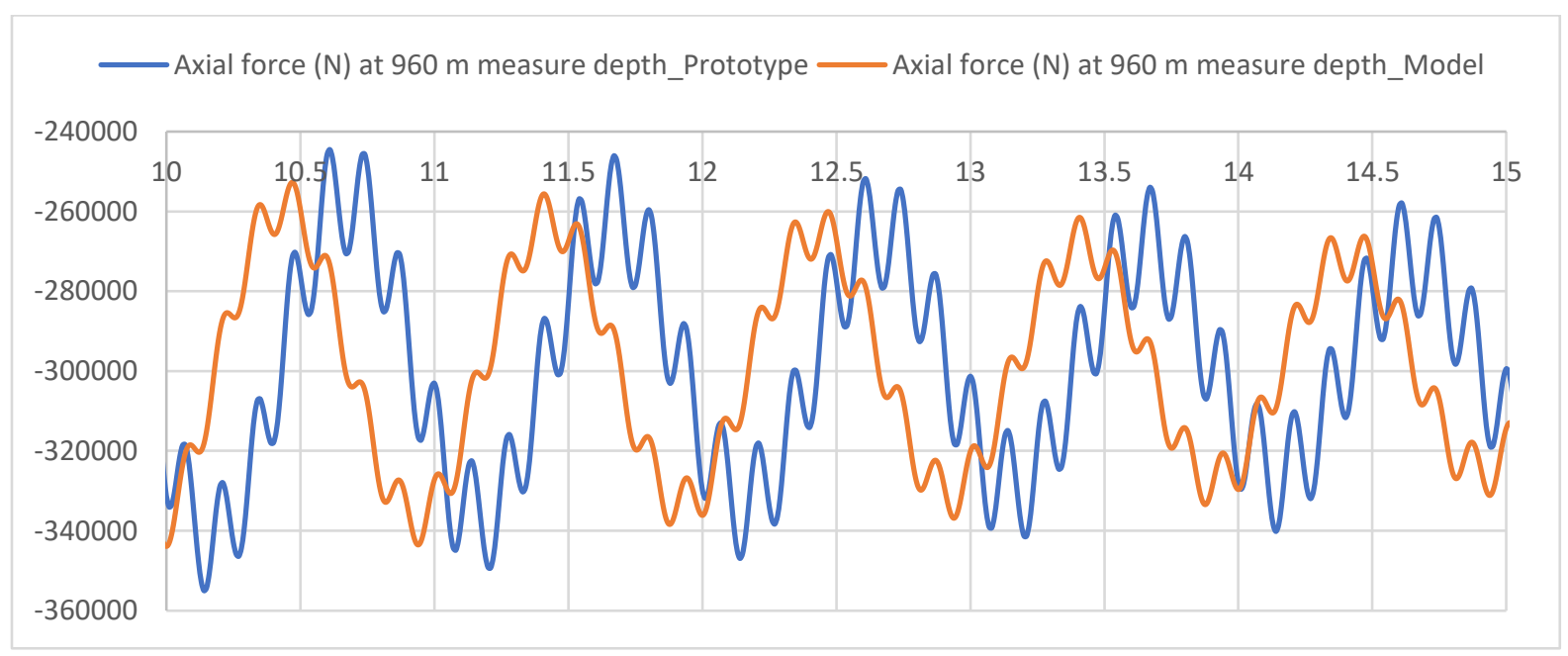

Figure 6. Comparison plots of the axial force at a 960-m measuring depth (MD) 


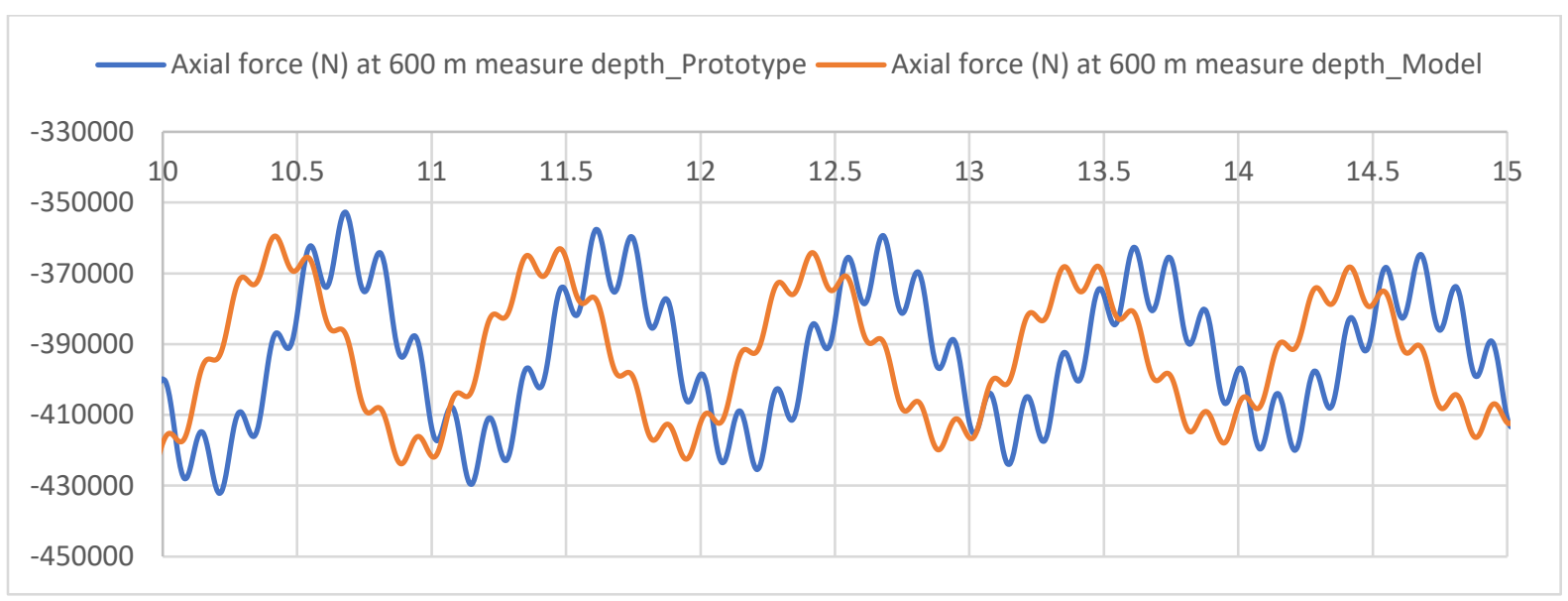

Figure 7. Comparison plots of the Axial force at a 600-m measuring depth (MD)

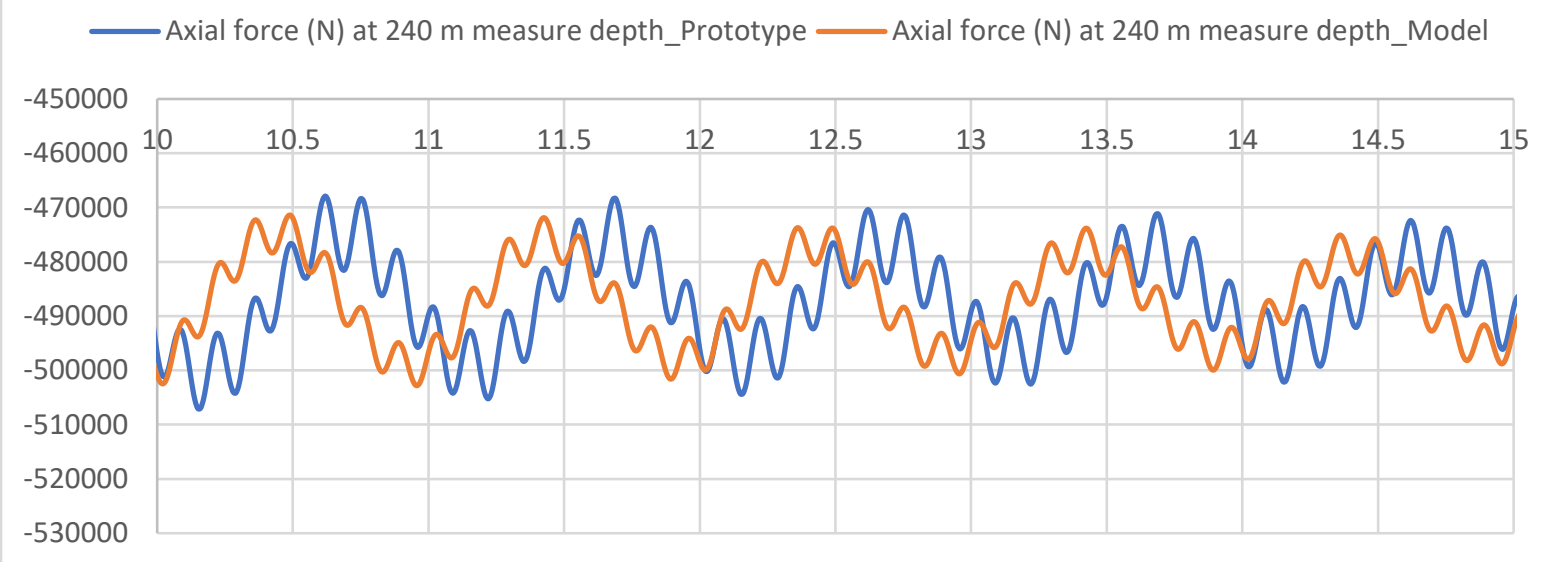

Figure 8. Comparison plots of the Axial force at a 240-m measuring depth (MD)

\section{CONCLUSIONS}

The similitude theory is a cost-effective and time-effective technique to establish similarity among structure systems, and discover, as well as validate proper scaling laws. Therefore, this study shows the importance, development, and applicability of the similitude relations of drillstring models made of the same materials, as well as the use of this relationship in the design and analysis of the models. The consideration of the geometrically distorted scaling technique provides useful scaling laws to design a laboratory scaled drillstring. In addition, the scaling relations were validated using the numerical simulations based on the lumped segments bond graph model technique, and the use of similitude relations to interpret the prototype's results using the developed model was presented. Based on the numerous analyses of the responses in time and frequency domains, the complete similarity between the full-size structure and the scaled model is easily achievable. Therefore, the method presented in the study is a potentially effective tool for solving the problems related to the drillstring vibrations.

\section{REFERENCES}

Aarrestad, T. V., \& Kyllingstad, A. (1988). An Experimental and Theoretical Study of a Coupling Mechanism Between Longitudinal and Torsional Drillstring Vibrations at the Bit. SPE Drilling Engineering, 3(01), 12-18. https://doi.org/10.2118/15563-PA

Antunes, J., Axisa, F., \& Hareux, F. (1992). Flexural vibrations of rotors immersed in dense fluids Part II: Experiments. Journal of Fluids and Structures, 6(1), 23-38. https://doi.org/10.1016/08899746(92)90053-6

Berlioz, A., Der Hagopian, J., Dufour, R., \& Draoui, E. (1996). Dynamic Behavior of a Drill-String: Experimental Investigation of Lateral Instabilities. Journal of Vibration and Acoustics, 118(3), 292298. https://doi.org/10.1115/1.2888180

David, F W, \& Nolle, H. (1982). Experimental Modelling in Engineering. Elsevier. 
https://doi.org/10.1016/C2013-0-00864-X

Eronini, I. E., Somerton, W. H., \& Auslander, D. M. (1982). A Dynamic Model for Rotary Rock Drilling. Journal of Energy Resources Technology, 104(2), 108-120. https://doi.org/10.1115/1.3230387

Finnie, I., \& Bailey, J. J. (1960). An Experimental Study of Drill-String Vibration. Journal of Engineering for Industry, 82(2), 129-135. https://doi.org/10.1115/1.3663020

Halsey, G. W., Kyllingstad, A., Aarrestad, T. V., \& Lysne, D. (1986, October). Drillstring Torsional Vibrations: Comparison Between Theory and Experiment on a Full-Scale Research Drilling Rig. Proceedings of SPE Annual Technical Conference and Exhibition. https://doi.org/10.2523/15564MS

Han, C., \& Yan, T. (2009). Analysis About Drill String Vibration of Horizontal Well. 2009 International Workshop on Intelligent Systems and Applications, 1-4. https://doi.org/10.1109/IWISA.2009.5072731

Jardine, S., Malone, D., \& Sheppard, M. (1994). Putting a damper on drilling's bad vibrations. Oilfield Review, January.

Jha, A., Sedaghati, R., \& Bhat, R. (2006). Analysis and Dynamic Testing of Structures Subjected to Vibration and Shock Using Scale Models. Canadian Aeronautics and Space Journal, 52(3), 95-108. https://doi.org/10.5589/Q06-012

Jha, A., Sedaghati, R., \& Bhat, R. (2005). Dynamic testing of structures using scale models. 46th AIAA/ASME/ASCE/AHS/ASC Structures, Structural Dynamics and Materials Conference, 9, 57315744. https://doi.org/10.2514/6.2005-2259

Karnopp, D. C., Margolis, D. L., \& Rosenberg, R. C. (2012). System dynamics : modeling, simulation, and control of mechatronic systems (5th ed.). Wiley.

Khadisov, M., Hagen, H., Jakobsen, A., \& Sui, D. (2020). Developments and experimental tests on a laboratory-scale drilling automation system. Journal of Petroleum Exploration and Production Technology, 10(2), 605-621. https://doi.org/10.1007/s13202-019-00767-6

Khulief, Y. A., \& Al-Naser, H. (2005). Finite element dynamic analysis of drillstrings. Finite Elements in Analysis and Design, 41(13), 1270-1288. https://doi.org/10.1016/j.finel.2005.02.003

Khulief, Y. A., \& Al-Sulaiman, F. A. (2009). Laboratory investigation of drillstring vibrations. Proceedings of the Institution of Mechanical Engineers, Part C: Journal of Mechanical Engineering Science, 223(10), 2249-2262. https://doi.org/10.1243/09544062JMES1550

Khulief, Y. A., Al-Sulaiman, F. A., \& Bashmal, S. (2007). Vibration analysis of drillstrings with self-excited stick-slip oscillations. Journal of Sound and Vibration, 299(3), 540-558. https://doi.org/10.1016/j.jsv.2006.06.065

Li, Z., Zhang, Y., Hou, X., Liu, W., \& Xu, G. (2004). ANALYSIS OF LONGITUDINAL AND TORSION VIBRATION OF DRILLSTRING. Gongcheng Lixue/Engineering Mechanics, 21(6), 203-210.

Loeken, E. A., Trulsen, A., Holsaeter, A. M., Wiktorski, E., Sui, D., \& Ewald, R. (2018). Design Principles Behind the Construction of an Autonomous Laboratory-Scale Drilling Rig. IFAC-PapersOnLine, 51(8), 62-69. https://doi.org/10.1016/j.ifacol.2018.06.356

Rao, S. S. (2011). Mechanical Vibrations (5th ed.). Prentice Hall.

Sarker, M. M. (2012). Modeling, simulation and control of stick-slip and bit-bounce vibration in an oil well brillstring. Memorial University of Newfoundland.

Sarker, M., \& Rideout, G. (2012). Dynamic Model of an Oilwell Drillstring with Stick-Slip and Bit-Bounce Interaction. 10th International Conference on Bond Graph Modeling and Simulation.

Tucker, W. R., \& Wang, C. (1999). An Integrated Model for Drill-String Dynamics. Journal of Sound and Vibration, 224(1), 123-165. https://doi.org/10.1006/jsvi.1999.2169

Wu, J.-J. (2007). Prediction of lateral vibration characteristics of a full-size rotor-bearing system by using those of its scale models. Finite Elements in Analysis and Design, 43(10), 803-816. https://doi.org/10.1016/j.finel.2007.05.001

Wu, J.-J., Cartmell, M. P., \& Whittaker, A. R. (2002). Prediction of the vibration characteristics of a fullsize structure from those of a scale model. Computers \& Structures, 80(18-19), 1461-1472. 
A Study of The Design Method and Similitude for A Small-Scale Test Drilling Rig (Part 1): An Application of The

https://doi.org/10.1016/S0045-7949(02)00095-0

YIGIT, A. S., \& CHRISTOFOROU, A. P. (2000). COUPLED TORSIONAL AND BENDING VIBRATIONS OF ACTIVELY CONTROLLED DRILLSTRINGS. Journal of Sound and Vibration, 234(1), 67-83. https://doi.org/10.1006/jsvi.1999.2854

Yigit, A.S., \& Christoforou, A. P. (1996). COUPLED AXIAL AND TRANSVERSE VIBRATIONS OF OILWELL DRILLSTRINGS. Journal of Sound and Vibration, 195(4), 617-627. https://doi.org/10.1006/jsvi.1996.0450

Yigit, Ahmet S., \& Christoforou, A. P. (2006). Stick-Slip and Bit-Bounce Interaction in Oil-Well Drillstrings. Journal of Energy Resources Technology, 128(4), 268-274. https://doi.org/10.1115/1.2358141 


\section{Appendix A}

An overview of the bond graph formalism

The bond graph is an explicit graphical tool for capturing the energetic structure of a physical system and is uniquely suited to the understanding of physical system dynamics. This formulation is suitable for hydraulics, mechatronics, thermodynamic and electric systems due to the ability to provide a concise description of complex systems. Furthermore, the bond graph language expresses a general class of physical systems through power (effort and flow) interactions, and the factors of power have different interpretations in different physical domains.

Figure A1 shows the generalized power (effort and flow) variables and energy (momentum and displacement) variables in some physical domains. The generalized inertias and capacitance in the bond graph store energy as a function of the system state variables. In addition, the sources provide inputs from the environment, while the generalized resistors remove energy from the system. The state variables are generalized momentum and dis-placement for inertias and capacitances, respectively, where the time derivatives of generalized momentum $\mathrm{p}$ and displacement $\mathrm{q}$ are generalized efforts $e$ and flow $f$. Changes of state are possible due to the power-conserving elements, including the power-continuous generalized transformer (TF) and gyrator (GY) elements which algebraically relate elements of the effort and flow vectors in and out of the element. In certain cases, for instance, the large motion of rigid bodies in which coordinate transformations are functions of the geometric state, the constitutive laws of these power-conserving elements are often state modulated. Also, the dynamic force equilibrium and velocity summations in rigid body systems are represented by power-conserving elements called 1 and 0 junctions, respectively.

\begin{tabular}{llll}
\hline Variable & General & Translation & Rotation \\
\hline Effort & $e(t)$ & Force & Torque \\
Flow & $f(t)$ & Velocity & $\begin{array}{l}\text { Angular } \\
\text { Velocity } \\
\text { Angular } \\
\text { momentum } \\
\text { Momentum }\end{array}$ \\
Displacement & $q=\int e d t$ & $\begin{array}{l}\text { Linear } \\
\text { momentum } \\
\text { displacement }\end{array}$ \\
Energy & $E(p)=\int f d t$ & Displacement & $\begin{array}{l}\text { Kinetic } \\
\text { Potential }\end{array}$ \\
& $E(q)=\int^{q} e d q$ & $\begin{array}{l}\text { Kinetic } \\
\text { potential }\end{array}$ & \\
\hline
\end{tabular}

Figure A1. The generalized bond graph quantities

\begin{tabular}{|c|c|c|c|c|c|c|c|}
\hline & SYMBOL & $\begin{array}{c}\text { CONSTITUTIVE LAW } \\
\text { (LINEAR) }\end{array}$ & $\begin{array}{c}\text { CAUSALITY } \\
\text { CONSIRAINIS } \\
\end{array}$ & & SYMBOL & $\begin{array}{c}\text { CONSTITUTIVELAW } \\
\text { (LINEAR) }\end{array}$ & \begin{tabular}{|c|} 
CAUSALITY \\
CONSTRAINIS \\
\end{tabular} \\
\hline \multicolumn{4}{|l|}{ SOURCES } & \multicolumn{4}{|c|}{ 2-PORT ELEMENTS } \\
\hline Flow & Sf $\longmapsto$ & $f=f(t)$ & fixed flow out & \multirow[t]{2}{*}{ Transformer } & \multirow{2}{*}{$\underset{\mathrm{n}}{1} \underset{\mathrm{TF}}{2}$} & \multirow{2}{*}{$\begin{array}{l}e_{2}=n e_{1} \\
f_{1}=n f_{2}\end{array}$} & \multirow{2}{*}{$\begin{array}{l}\text { effort in - effort } \\
\text { out, or flow in- } \\
\text { flow out }\end{array}$} \\
\hline Effort & $\mathrm{Se} \longrightarrow \mathrm{C}$ & $e=e(t)$ & fixed effort out & & & & \\
\hline \multicolumn{4}{|c|}{ ENERGETIC ELEMENIS } & \multirow{2}{*}{$\begin{array}{l}\text { Modulated } \\
\text { Transformer }\end{array}$} & \multirow{2}{*}{ 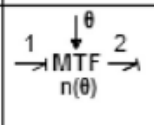 } & \multirow{2}{*}{$\begin{array}{l}e_{2}=n(\theta) e_{1} \\
f_{1}=n(\theta) f_{2}\end{array}$} & \\
\hline \multirow[t]{2}{*}{ Inertia } & & $f=\frac{1}{I} \int e d t$ & $\begin{array}{l}\text { preferred } \\
\text { integral }\end{array}$ & & & & \\
\hline & $\longmapsto 1$ & $e=I \frac{d f}{d t}$ & & Gyrator & $\stackrel{1}{\mathrm{GY}_{\mathrm{n}}} \stackrel{2}{\longrightarrow}$ & $\begin{array}{l}e_{2}=n f_{1} \\
e_{1}=n f_{2}\end{array}$ & $\begin{array}{l}\text { flow in-flow out, } \\
\text { or effort in-effort } \\
\text { out }\end{array}$ \\
\hline Capacitor & $\begin{array}{l}\mapsto C \\
\rightarrow C\end{array}$ & $\begin{array}{l}\varepsilon=\frac{1}{C} \int f d t \\
f=C \frac{d \varepsilon}{d t}\end{array}$ & $\begin{array}{l}\text { preferred } \\
\text { integral }\end{array}$ & $\begin{array}{l}\text { Modulated } \\
\text { Gyrator }\end{array}$ & 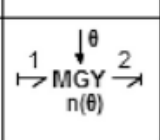 & $\begin{array}{l}e_{2}=n(\theta) f_{1} \\
e_{1}=n(\theta) f_{2}\end{array}$ & \\
\hline \multirow[t]{2}{*}{ Resistor } & $\mapsto \mathrm{R}$ & $\epsilon^{\prime}=R f$ & none & \multicolumn{4}{|c|}{ CONSTRAINT NODES } \\
\hline & $\rightarrow R$ & $f=\frac{1}{2} g$ & & 1-junction & $\frac{1}{\sqrt{3}} \stackrel{2}{\longrightarrow}$ & $\begin{array}{l}e_{2}=e_{1}-e_{3} \\
f_{1}=f_{2} \\
f_{3}=f_{2}\end{array}$ & one flow input \\
\hline
\end{tabular}

Figure A2. The bond graph elements 


\section{Appendix B}

The Bond Graph Drillstring Model

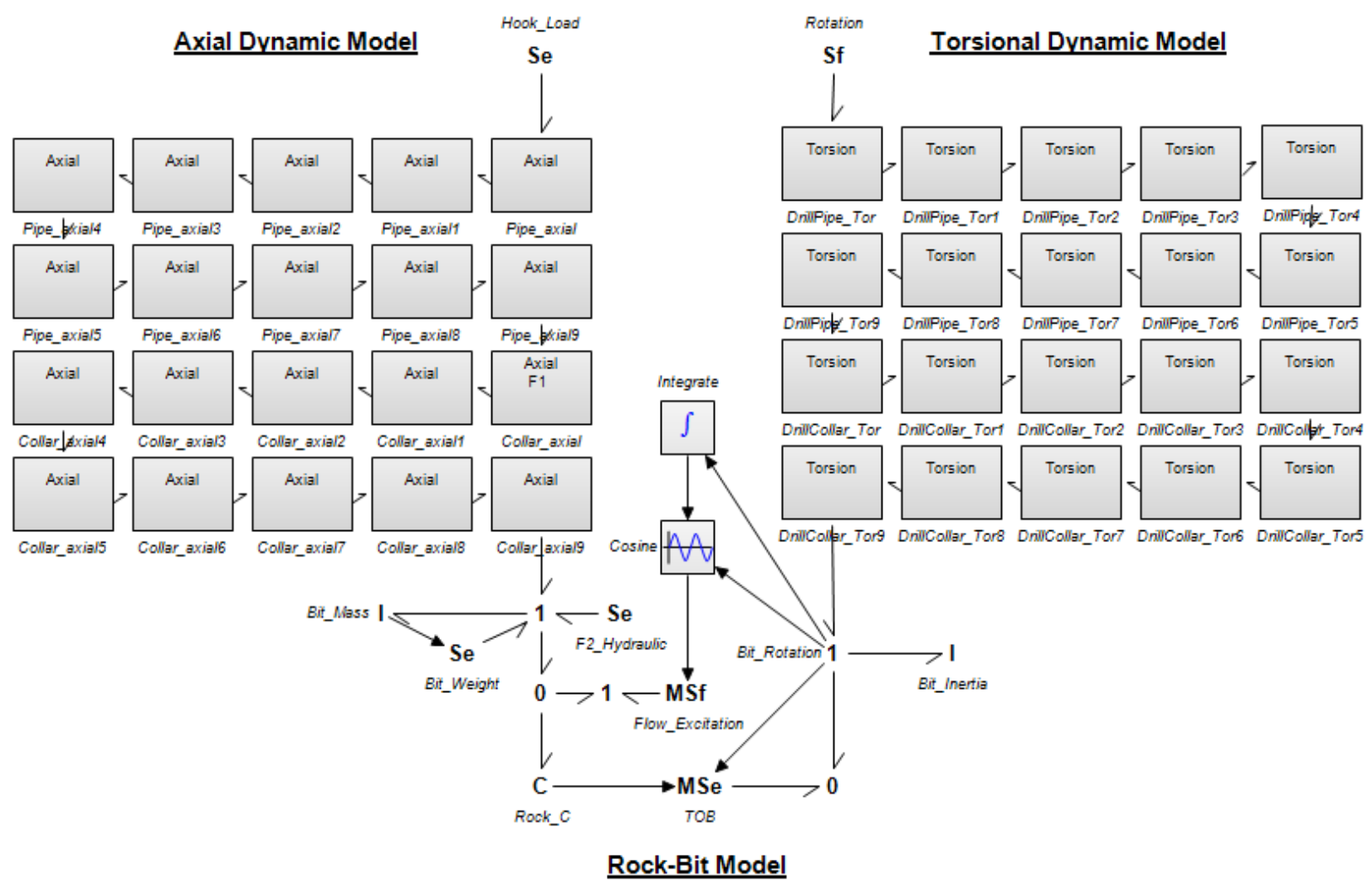

Figure B1. The bond graph numerical model of a rotary drillstring.

\section{ABOUT THE AUTHOR}

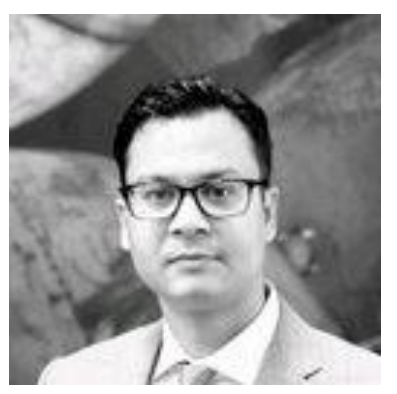

Dr. Mejbahul Sarker is a faculty member at the American University of Kurdistan, Iraq, and possesses over 10 years of diversified professional experience in entrepreneurship, oil and gas, as well as academia. Dr. Sarker obtained a BSc in mechanical engineering from Bangladesh University of Engineering and Technology (BUET) in 2008, and also obtained a Master's degree and a Ph.D. in petroleum engineering from the Memorial University of Newfoundland, Canada in 2012 and 2016, respectively. Before joining the American University of Kurdistan as a lecturer in 2019, he worked with AGAT geology laboratory (2018-2019) as a Laboratory Coordinator. Dr. Sarker has also volunteered with the Society of Petroleum Engineers at the Memorial University of Newfoundland and the University of Calgary, in Canada. 